\title{
ELECTRONIC AND STERIC EFFECTS IN GOLD(I) PHOSPHINE THIOLATE COMPLEXES
}

\author{
Janet Foley, Raymond C. Fort, Jr., Katherine McDougal, \\ Mitchell R. M. Bruce, and Alice E. Bruce* \\ Department of Chemistry, University of Maine, Orono, ME 04469-5706, USA
}

The unusual yellow color of $\mathrm{Au}_{2}(\mathrm{dppm})(\mathrm{SR})_{2}(\mathrm{R}=4$-tolyl; dppm = diphenylphosphinomethane) is attributed to a red-shift in the $S \rightarrow A u$ charge transfer caused by destabilization of the sulfur highest occupied molecular orbital (HOMO). Variable temperature experiments show two broad bands at $-80^{\circ} \mathrm{C}$ in the ${ }^{31} \mathrm{P}\left\{{ }^{1} \mathrm{H}\right\} \mathrm{NMR}$ spectrum of $\mathrm{Au}_{2}(\mathrm{dppm})(\mathrm{SR})_{2}$ and the activation energy for interconversion is $10 \mathrm{kcal} / \mathrm{mol}$. Only one sharp band is observed down to $-80^{\circ} \mathrm{C}$ in the spectrum of the white complex, $\mathrm{Au}_{2}$ (dppe)(SR)2 (dppe = diphenylphosphinoethane). Molecular mechanics calculations on $\mathrm{Au}_{2}(\mathrm{dppm})(\mathrm{SR})_{2}$ and $\mathrm{Au}_{2}(\mathrm{dppe})(\mathrm{SR})_{2}$ reveal that, for $\mathrm{Au}_{2}$ (dppe)(SR)2, a series of maxima and minima, separated by $2.5 \mathrm{kcal} / \mathrm{mol}$, occur every $120^{\circ}$. which is consistent with rotation around an unhindered carbon-phosphorus single bond. The $\mathrm{Au}$ atoms are not within bonding distance in any conformation. Computational results for $\mathrm{Au}_{2}(\mathrm{dppm})(\mathrm{SR})_{2}$ indicate one minimum energy structure in which the Au-P bonds are anti. There is a high energy conformation $(9 \mathrm{kcal} / \mathrm{mol}$ above the global minimum) where overlap between golds is maximized. The implications of gold-gold bonding in this complex are discussed. The steric influence of the thiolate ligand has been examined by synthesizing a series of dinuclear gold $(I)$ complexes in which the steric properties of the thiolate are varied: $\mathrm{Au}_{2}(\mathrm{dppm})(\mathrm{SR})_{2}(\mathrm{R}=2,6$-dichlorophenyl; 2,6-dimethylphenyl; 3,5-dimethylphenyl). The 2,6-disubstituted complexes are white, while the 3,5-dimethyl complex is yellow. These results, along with VT-NMR experiments, are consistent with the conclusion that the more sterically-bulky thiolates hinder the close approach of the golds in the dinuclear complexes.

\section{Introduction}

During the last decade, interest in gold chemistry has increased for several reasons, the most important one being that certain gold $(I)$ thiolate compounds are very effective drugs for the treatment of rheumatoid arthritis, a poorly-understood disease that afflicts millions of people each year. ${ }^{1}$ The therapeutic benefits of gold have also prompted testing of gold(I) phosphine and thiolate compounds for anticancer activity and inhibition of the HIV-1 virus. ${ }^{2}$ In addition to interest in the biological activity of gold, the intriguing phenomenon of attractive interactions between closed shell gold(I) atoms ([Xe4f $\left.{ }^{14} 5 d^{10}\right)$, has stimulated numerous experimental and theoretical studies. ${ }^{3}$ Material scientists have also long been interested in gold and in a recent report of the use of gold as a sensor for thiols, the authors commented on the need for more studies of the fundamental properties and reactivities of gold-thiolate compounds. ${ }^{4}$

Several years ago, our group initiated studies of the electronic structure and reactivity of neutral gold(I) phosphine thiolate complexes. ${ }^{5}$ Our interest in these complexes is motivated by their similarity to Auranofin, an orally active anti-arthritis gold $(I)$ drug that contains triethylphosphine and thiolate ligands. We recently reported the synthesis and characterization of several classes of dinuclear and mononuclear gold $(I)$ complexes containing phosphine and thiolate ligands (series A-C, see below). ${ }^{5 a}$ All of the complexes in series A are white with the exception of $\mathbf{A 1}$, which is bright yellow, an atypical color for linear two-coordinate gold(I). The UV-vis spectra are similar for all complexes, consisting of intense absorbances above $40,000 \mathrm{~cm}^{-1}(<250 \mathrm{~nm})$ followed by a series of poorly defined shoulders at lower energy. Spectral fitting procedures were used to deconvolute the spectra into a series of Gaussian bands (see Figure 1). ${ }^{5 \mathrm{a}}$

Classical techniques involving changing the solvent polarity and varying the ligand electronic properties were used to assign the two lowest energy transitions as sulfur-to-gold charge transfers 


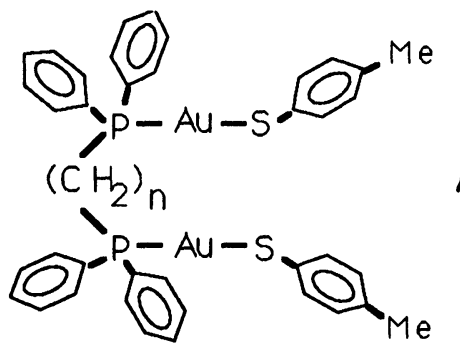

A

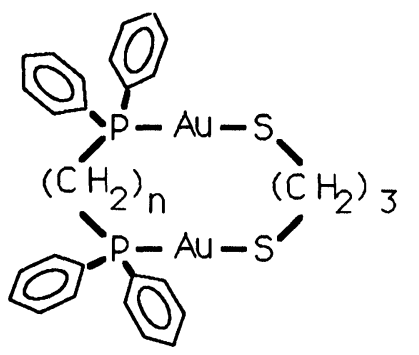

$\begin{array}{lllll}n=1 & 2 & 3 & 4 & 5 \\ \text { A1 } & \text { A2 } & \text { A3 } & \text { A4 } 4 & \text { A5 }\end{array}$

B<smiles>[Y10]c1ccc(S[Al][PH]([R])([R])[R])cc1</smiles>

$$
n=\begin{array}{llll}
2 & 3 & 4 & 5 \\
\text { B1 } & \text { B2 } & \text { B3 } & \text { B4 }
\end{array}
$$

C $\quad \mathrm{R}=\mathrm{Ph} \mathrm{Me}$

C1 C2

$(\mathrm{S} \rightarrow \mathrm{Au} C T){ }^{6}$ In all the complexes except A1, the $\mathrm{S} \rightarrow \mathrm{Au}$ CT's occur in the UV, whereas in $\mathrm{A1}$ the lowest energy band is red-shifted by $2500 \mathrm{~cm}^{-1}$ into the visible, hence the yellow color of A1 (see Table I). The red-shift could result from destabilization of the highest occupied molecular orbital

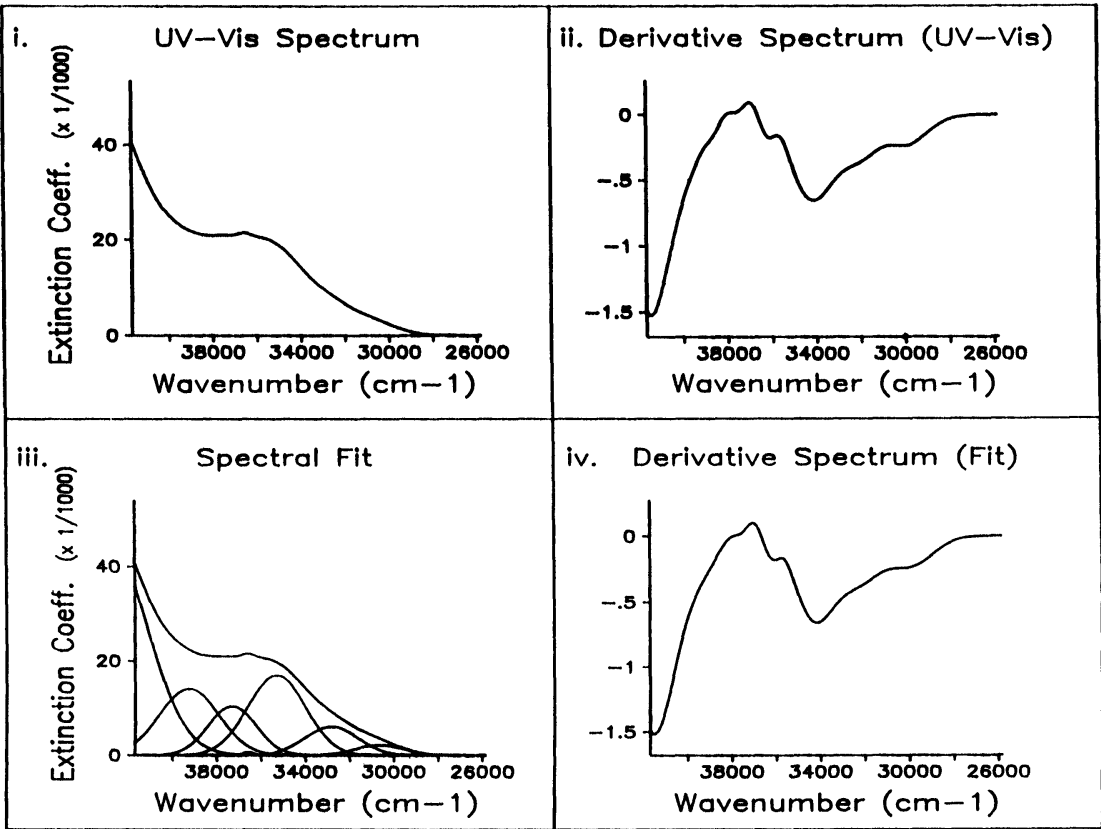

Figure 1. UV-visible absorption and derivative spectra for $\left[A u_{2}(d p p p n)(p-t c)_{2}\right]$ (A5). (i) experimental absorption spectrum; (ii) experimental derivative spectrum; (iii) spectral fit for absorption spectrum; (iv) spectral fit for derivative. (Reprinted with permission from Narayanswamy, R; Young, M. A.; Parkhurst, E.; Ouellette, M.; Kerr, M. E.; Ho, D. M.; Elder, R. C.; Bruce, A. E.; Bruce, M. R. M. Inorg. Chem., 1993, 32, 2202. Copyright 1993 American Chemical Society. 
(sulfur), stabilization of the lowest unoccupied molecular orbital (gold), or a combination of both. Variable temperature NMR experiments and molecular mechanics computations on A1 and A2 provide insight to the reason for the red shift in the UV-vis spectrum of A1. ${ }^{7}$

Table I. Electronic Absorption Spectral Features of selected Gold(I) Phosphine Thiolate Complexes. Comparison of Absorption Bands, $\mathrm{cm}^{-1}$, and (extinction coefficients).

\begin{tabular}{lllllc}
\hline $\mathrm{Au}\left(\mathrm{PPh}_{3}\right)(p-\mathrm{tc})$ & $\mathrm{Au}_{2}(\mathrm{dpppn})(\mathrm{p}-\mathrm{tc})_{2}$ & $\mathrm{Au}_{2}(\mathrm{dppm})(p-\mathrm{tc})_{2}$ & Assignment \\
\hline $3.0 \times 10^{4}\left(1 \times 10^{3}\right)$ & $3.05 \times 10^{4}$ & $\left(2 \times 10^{3}\right)$ & $2.8 \times 10^{4}$ & $\left(3 \times 10^{3}\right)$ & LMCT $(\mathrm{S} \rightarrow \mathrm{Au})$ \\
$3.25 \times 10^{4}\left(3 \times 10^{3}\right)$ & $3.3 \times 10^{4}\left(6 \times 10^{3}\right)$ & $3.1 \times 10^{4}$ & $\left(6 \times 10^{3}\right)$ & LMCT $(\mathrm{S} \rightarrow \mathrm{Au})$ \\
$3.5 \times 10^{4}\left(7 \times 10^{3}\right)$ & $3.55 \times 10^{4}\left(2 \times 10^{4}\right)$ & $3.45 \times 10^{4}\left(2 \times 10^{4}\right)$ & IL $(p-\mathrm{tc})$ \\
$3.6 \times 10^{4}\left(8 \times 10^{2}\right)$ & $3.65 \times 10^{4}\left(7 \times 10^{2}\right)$ & $3.6 \times 10^{4}$ & $\left(3 \times 10^{2}\right)$ & $\pi \rightarrow \pi^{*}$ \\
$3.7 \times 10^{4}\left(8 \times 10^{3}\right)$ & $3.75 \times 10^{4}\left(1 \times 10^{4}\right)$ & $3.7 \times 10^{4}$ & $\left(1 \times 10^{4}\right)$ & $n \rightarrow \pi^{*}$ \\
$3.85 \times 10^{4}\left(3 \times 10^{3}\right)$ & $3.9 \times 10^{4}\left(1 \times 10^{4}\right)$ & $3.9 \times 10^{4}$ & $\left(1 \times 10^{4}\right)$ &
\end{tabular}

\section{Materials and Methods}

Reagents and Instrumental Details. Bis(diphenylphosphino)methane and bis(diphenylphosphino)ethane were purchased from Aldrich or Strem and used as received. $\mathrm{HAuCl}_{4} \cdot 3 \mathrm{H}_{2} \mathrm{O}$ was obtained from Aldrich or Aithaca. The thiols, $p$-thiocresol (4-methylthiophenol), 4-chlorothiophenol, 3,5-dimethylthiophenol, 2,6-dimethylthiophenol, and 2,6-dichlorothiophenol were purchased from Aldrich. Bis(p-chlorophenyl)disulfide was purchased from ChemService. Cambridge Isotope Labs supplied $\mathrm{CD}_{2} \mathrm{Cl}_{2}$ used for NMR experiments. The ${ }^{31} \mathrm{P}\left\{{ }^{1} \mathrm{H}\right\}$ NMR data were obtained on a Varian XL-200 FT-NMR spectrometer operating at $81 \mathrm{Mz}$ and chemical shifts are referenced to external $85 \% \mathrm{H}_{3} \mathrm{PO}_{4}$. Variable-temperature NMR experiments were carried out from +20 to $-80^{\circ} \mathrm{C}$ on $0.035 \mathrm{M}$ and $0.07 \mathrm{M}$ solutions of $\mathrm{A} 1$ and ca. $0.07 \mathrm{M}$ solutions of $\mathrm{A2}$ in $\mathrm{CD}_{2} \mathrm{Cl}_{2}$.

Synthesis and Abbreviations. Complexes A1 and A2 are prepared as air stable, microcrystalline solids by using procedures previously described. ${ }^{5 a}$ The complexes in series $D$ are prepared in a similar fashion, by using thiolate substitution reactions of the corresponding dinuclear gold(I) phosphine chloride complexes. The following abbreviations are used: $\mathrm{dppm}=$ bis(diphenylphosphino)methane; dppe $=1,2$-bis(diphenylphosphino)ethane; $p$-tc $=p$-thiocresol.

Computational Methodology. Molecular mechanics calculations were performed on a Gateway 200 486DX2 (66Mhz, 16Mb memory), employing the program PCModel. ${ }^{8}$ PCModel contains the MMX force field, which incorporates both $\mathrm{MM}^{2}{ }^{9}$ and $M M 3^{10}$ parameterization, as well as additional parameters developed by Serena. Aromatic carbons (type 40) were used for the benzene rings; no $\pi$-VESCF calculations were performed. The program implements a set of generalized force constants for transition metal atoms, and uses standard covalent radii: for example, $1.455 \AA$ for gold. These parameters result in realistic geometries for simple coordination

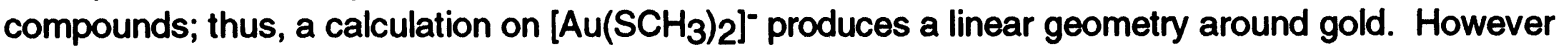
PCModel contains no parameters for repulsions between transition metals. Standard bond lengths provided by the program were used (e.g. Au-P $=2.47 \AA$ and $A u-S=2.49 \AA$ ) and the bond lengths were not fixed for the calculations reported here. Additional calculations carried out with bond lengths fixed at values more characteristic for $A u(I)-P(2.26 \AA)$ and $A u(I)-S(2.3 \AA)$ bonds, gave similar results, however the total energy was higher due to increased steric interactions. Complexes A1 and A2 were minimized at arbitrary geometries and the ROT E function, which utilizes the rigid rotor approximation, was employed to locate additional minima. Structures so located were subjected to full geometry optimization, including vibrational annealing at $300 \mathrm{~K}$.

The dihedral driver of PCModel was used to calculate conformational energy profiles for each complex. The dihedral angles, $\phi_{1}$ and $\phi_{2}$ for $A 1$ and $\phi_{3}$ for $A 2$ are defined as illustrated in 
Scheme I. Two dihedrals were defined for A1 for the purpose of carrying out a double dihedral drive calculation. For single dihedral drive computations, a full geometry optimization was carried out for every $5^{\circ}$ rotation in dihedral angle $\left(\phi_{1}\right.$ or $\left.\phi_{3}\right)$ beginning at $0^{\circ}$. For the double dihedral drive computation, $\phi_{2}$ was rotated by $60^{\circ}$ increments and a full geometry optimization was carried out for every $5^{\circ}$ rotation in $\phi_{1}$ beginning at $0^{\circ}$. Distances between gold atoms were determined by using the QUERY command. There are discontinuities in the conformational energy profiles at the starting and ending dihedrals; e.g. at $0^{\circ}$ and $360^{\circ}$ in Figure 3. Discrepancies in energy of several $\mathrm{kcal} / \mathrm{mol}$ for conformations at the starting and ending points of the dihedral drive computation are typical when those points lie in regions of relatively steep slope. Resetting initial and final points brings the results of different computations into agreement in these regions within $0.2 \mathrm{kcal} / \mathrm{mol}$.

\section{SCHEME I}
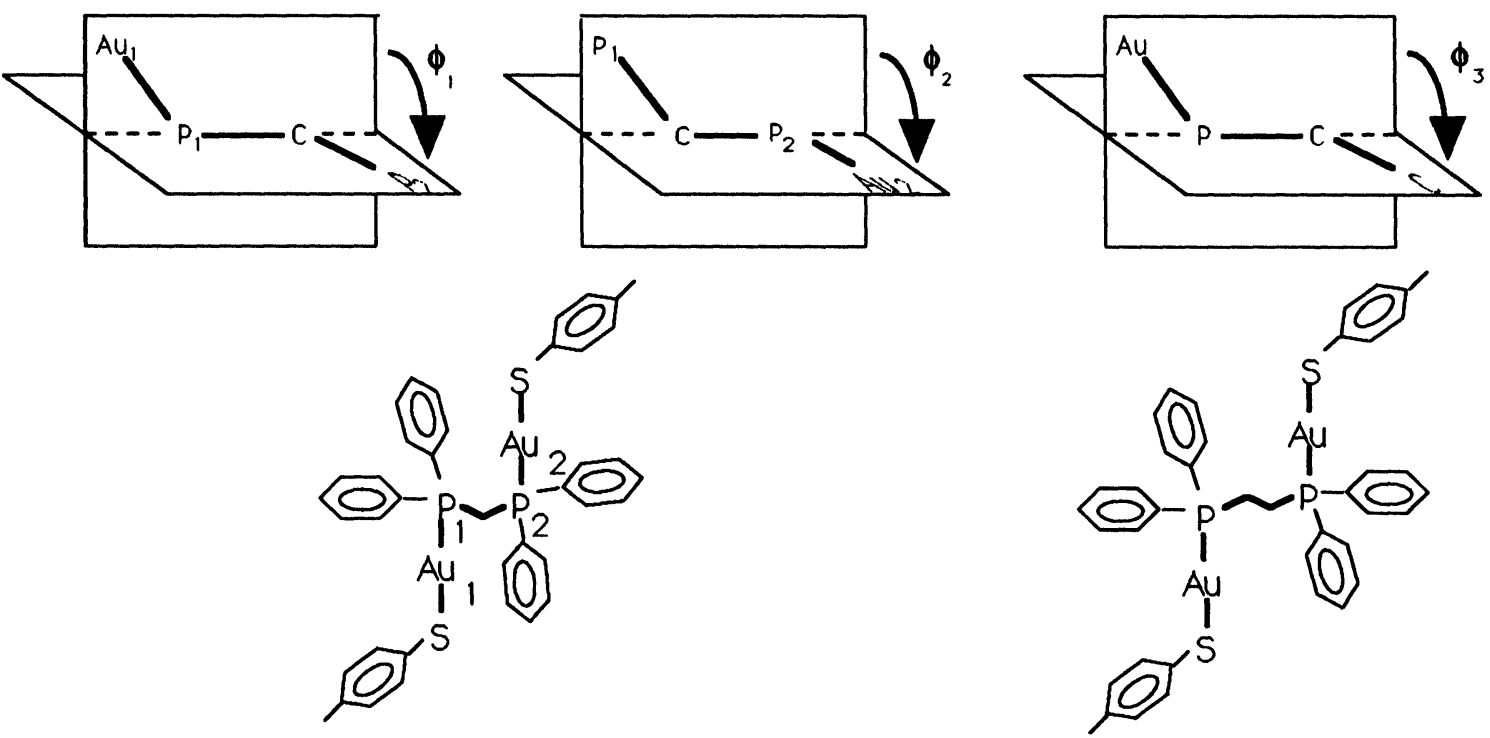

\section{Results and Discussion}

Variable Temperature ${ }^{31} \mathrm{P}\left\{{ }^{1} \mathrm{H}\right\}$ NMR Experiments. At room temperature, each of the complexes in series A-C exhibits a singlet in the ${ }^{31} \mathrm{P}\left\{{ }^{1} \mathrm{H}\right\}$ NMR spectrum between 28 and $37 \mathrm{ppm}$, a region that is typical for neutral, two-coordinate gold $(I)$ complexes. Variable temperature NMR experiments on $\mathrm{A} 4^{5 \mathrm{a}}$ and $\mathrm{A} 2$ reveal a singlet for each complex down to $-80^{\circ} \mathrm{C}$, consistent with the equivalence of all phosphorus atoms in solution (Figure 2a). In contrast, complex A1 shows two broad peaks at $-80^{\circ} \mathrm{C}$ at 30.1 and $32.2 \mathrm{ppm}$ (Figure 2b). $5 \mathrm{a}$ An activation energy of $10 \mathrm{kcaVmol}$ was calculated from line shape analysis using a coalescence temperature of $-60{ }^{\circ} \mathrm{C}$ and a peak separation at the low temperature limit of $170 \mathrm{~Hz}$. Rotation about C-P single bonds can occur with activation energies near $10 \mathrm{kcal} / \mathrm{mol} .^{11}$ However, the absence of a temperature dependent process for A2 suggests that C-P bond rotation in the open-chain complexes (series A) have much lower activation energies. Molecular mechanics calculations were carried out to gain insight into the conformational preferences and barriers to rotation predicted for A1 and A2. 


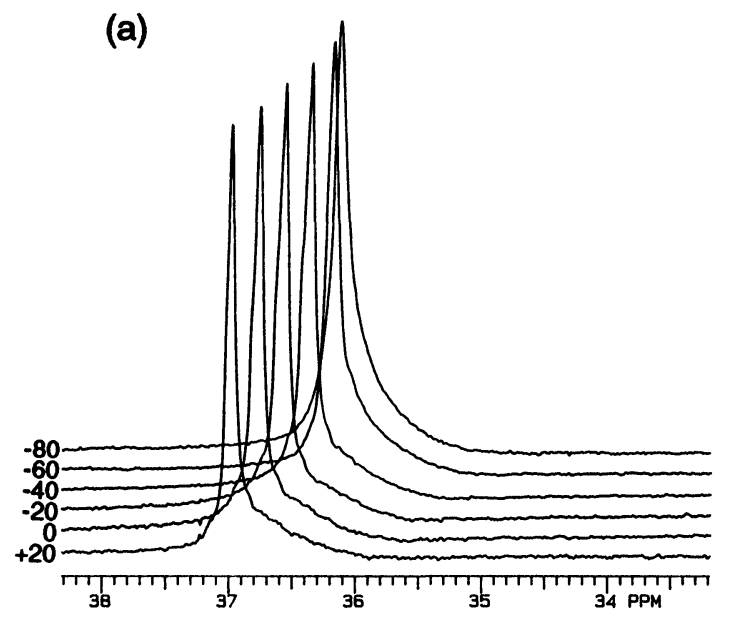

(b)

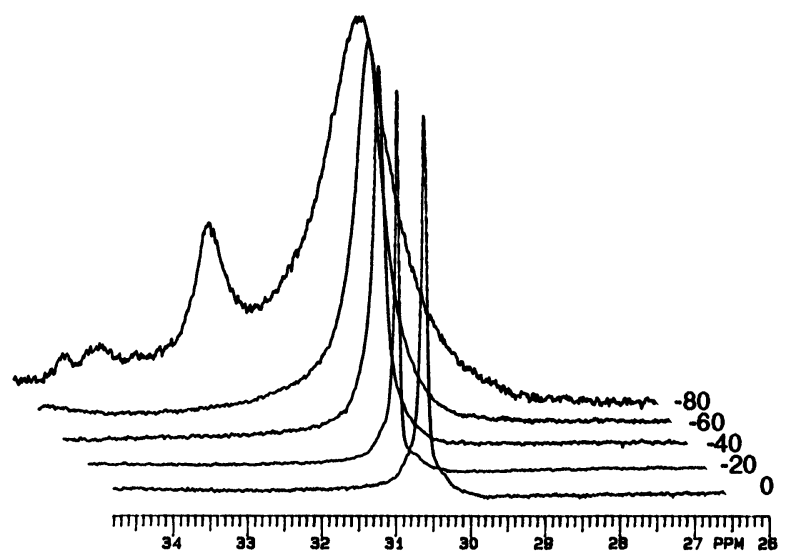

Figure 2. Variable temperature ${ }^{31} \mathrm{P}$ NMR spectra in $\mathrm{CD}_{2} \mathrm{Cl}_{2}$ from -80 to $+20{ }^{\circ} \mathrm{C}$ as indicated: (a) $\left[\mathrm{Au}_{2}(\mathrm{dppe})(p-t c)_{2}\right](\mathbf{A 2})$, no offset; (b) $\left[\mathrm{Au}_{2}(\mathrm{dppm})(p-t c)_{2}\right]$ (A1), spectra offset for clarity.
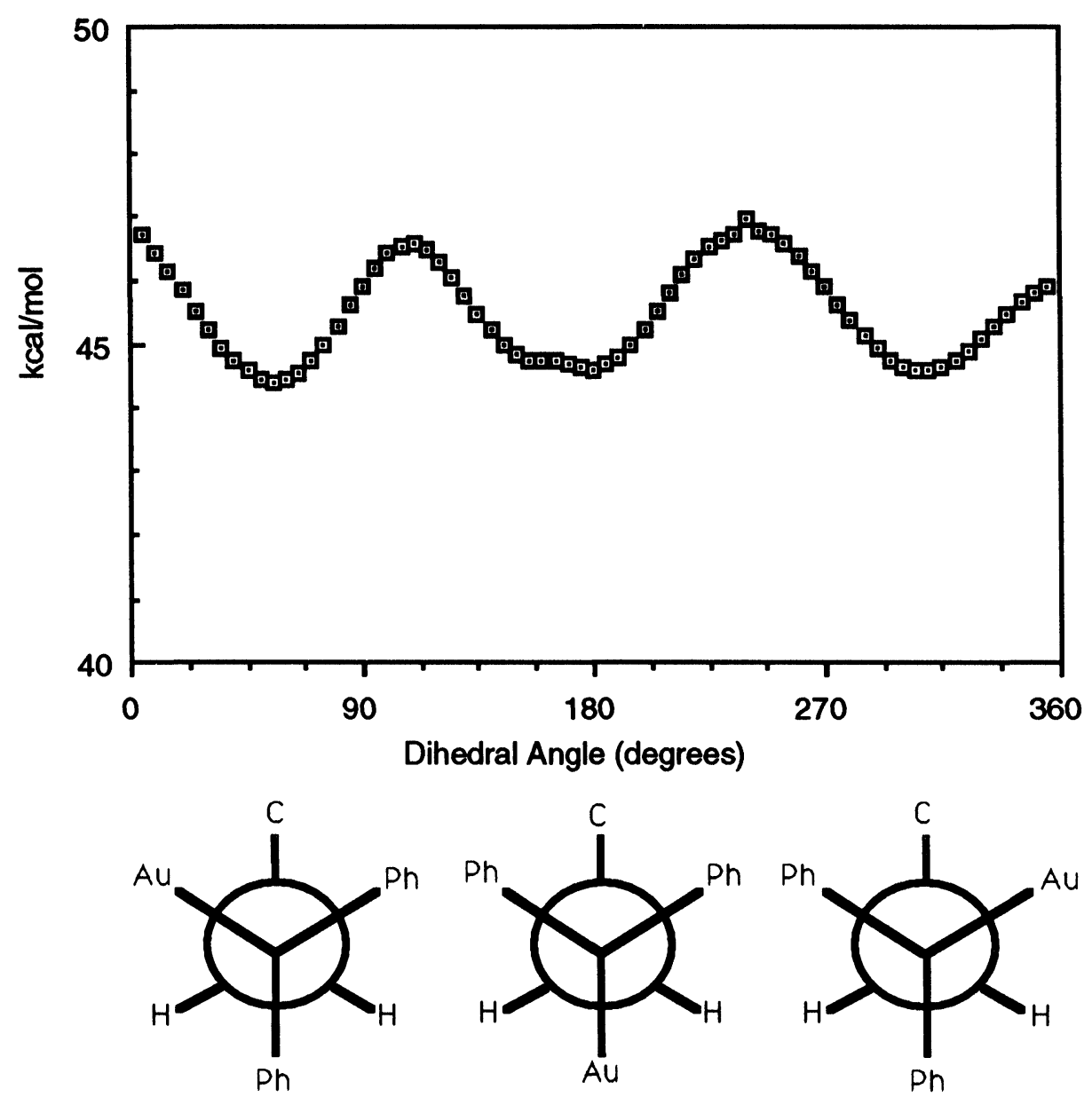

Figure 3. Conformational energy profile and Newman projections for staggered geometries of $\left[\mathrm{Au}_{2}(\mathrm{dppe})(p-\mathrm{tc})_{2}\right](\mathrm{A2})$. 
Conformational Analysis of $\mathrm{Au}_{2}(\mathrm{dpp \theta})(\mathrm{p}-\mathrm{tc})_{2}$ (A2). The conformational energy profile for A2, is shown in Figure 3. A series of maxima and minima, separated by only $2.5 \mathrm{kcal} / \mathrm{mol}$, are observed for rotation about the C-P bond in A2. The maxima and minima occur every $120^{\circ}$, corresponding to approximately eclipsed and staggered conformations, respectively. The closest approach of gold atoms is greater than $4 \AA$. The barrier for rotation of $A 2$ is small compared to the available thermal energy at $-80^{\circ} \mathrm{C}$. The molecular mechanics calculation is therefore consistent with VT-NMR experimental data that shows only one conformation of $A 2$ in the temperature range -80 to $20^{\circ} \mathrm{C}$.

Conformational Analysis of $\mathrm{Au}_{2}(\mathrm{dppm})(\boldsymbol{p}-\mathrm{tc})_{2}(\mathrm{~A} 1)$. The conformational energy profile for A1, shown in Figure 4, is not symmetrical as is observed for A2. The large asymmetry in the energy profile can be attributed to the more severe intramolecular steric effects between phenyl rings in the dppm ligand compared to the dppe ligand. As a result, the $60^{\circ}$ and $300^{\circ}$ conformations are not equivalent in energy as might be expected by a view of simple Newman projections (see bottom of Figure 4). These Newman projections are misleading since they imply that the total energy depends only on the described dihedral $\left(\phi_{1}\right)$, when in fact, other dihedrals are minimized to structures that do not necessarily correspond to the pathway connecting two fully enantiomeric structures.

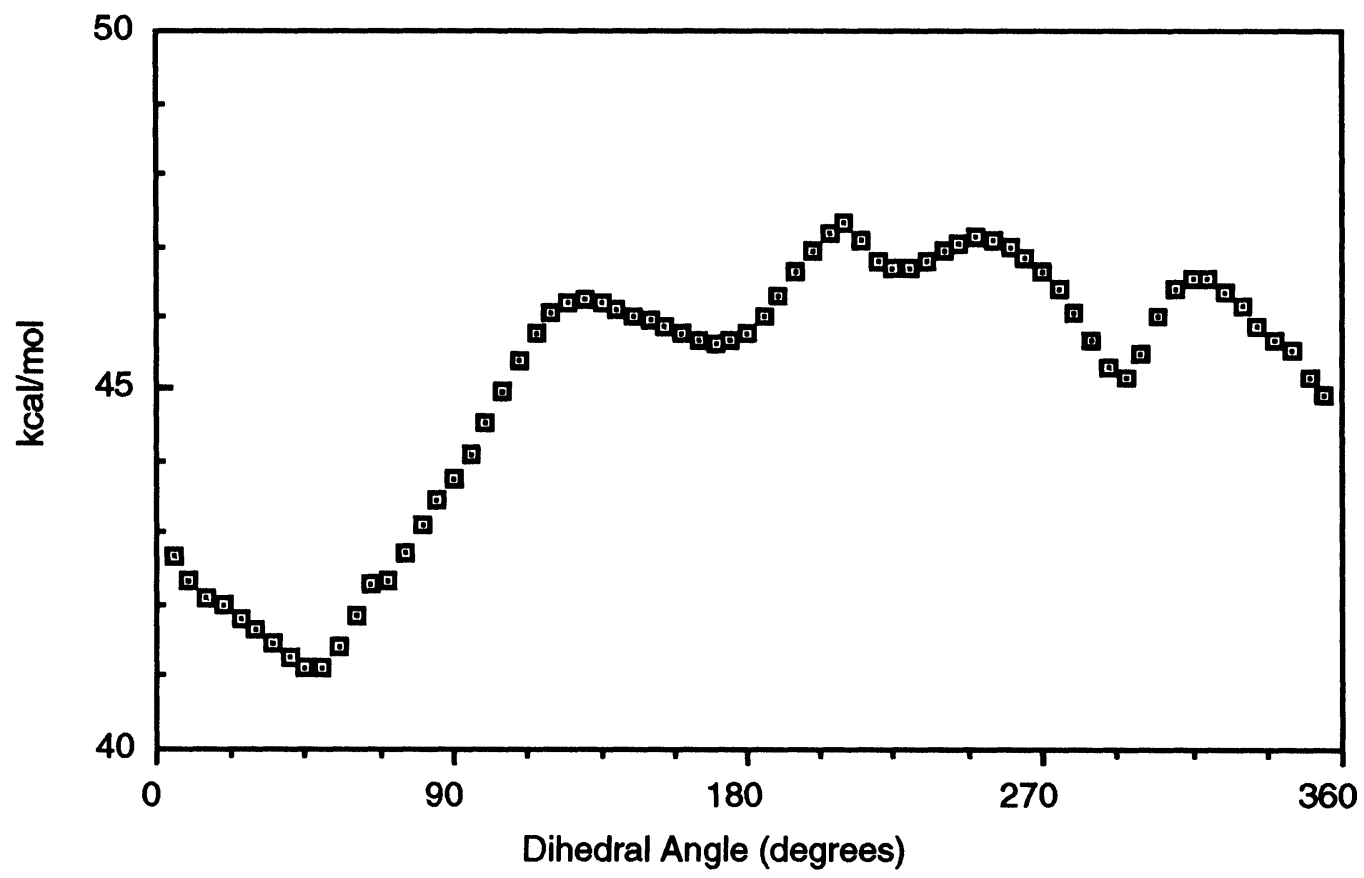

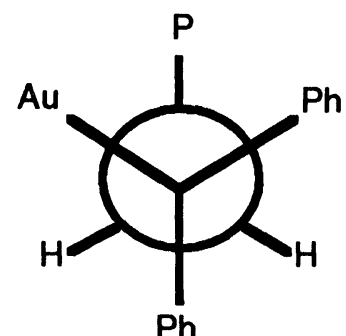

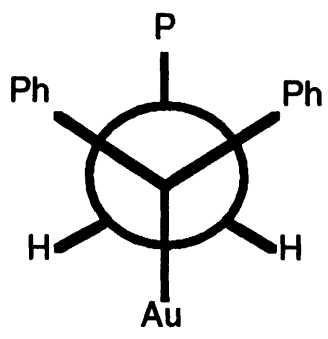

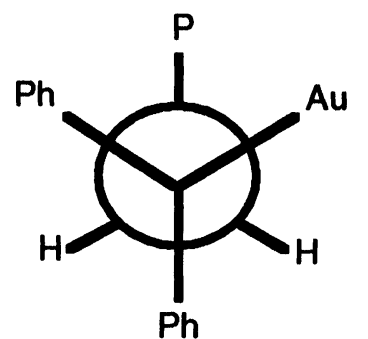

Figure 4. Conformational energy profile and Newman projections for staggered geometries of $\left[\mathrm{Au}_{2}(\mathrm{dppm})(\mathrm{p}-\mathrm{tc})_{2}\right](\mathbf{A 1})$. 
The unsymmetrical appearance of the energy profile prompted us to question whether a single dihedral drive computation of A1 provided enough information about the accessibility of conformations. A more complete understanding of the conformational preferences can be obtained by a double dihedral drive calculation. (See Scheme I for definitions of $\phi_{1}$ and $\phi_{2}$.) The results for such a calculation, carried out on A1 as described in the Computational Methodology section, are shown as a 3-dimensional plot in Figure 5.

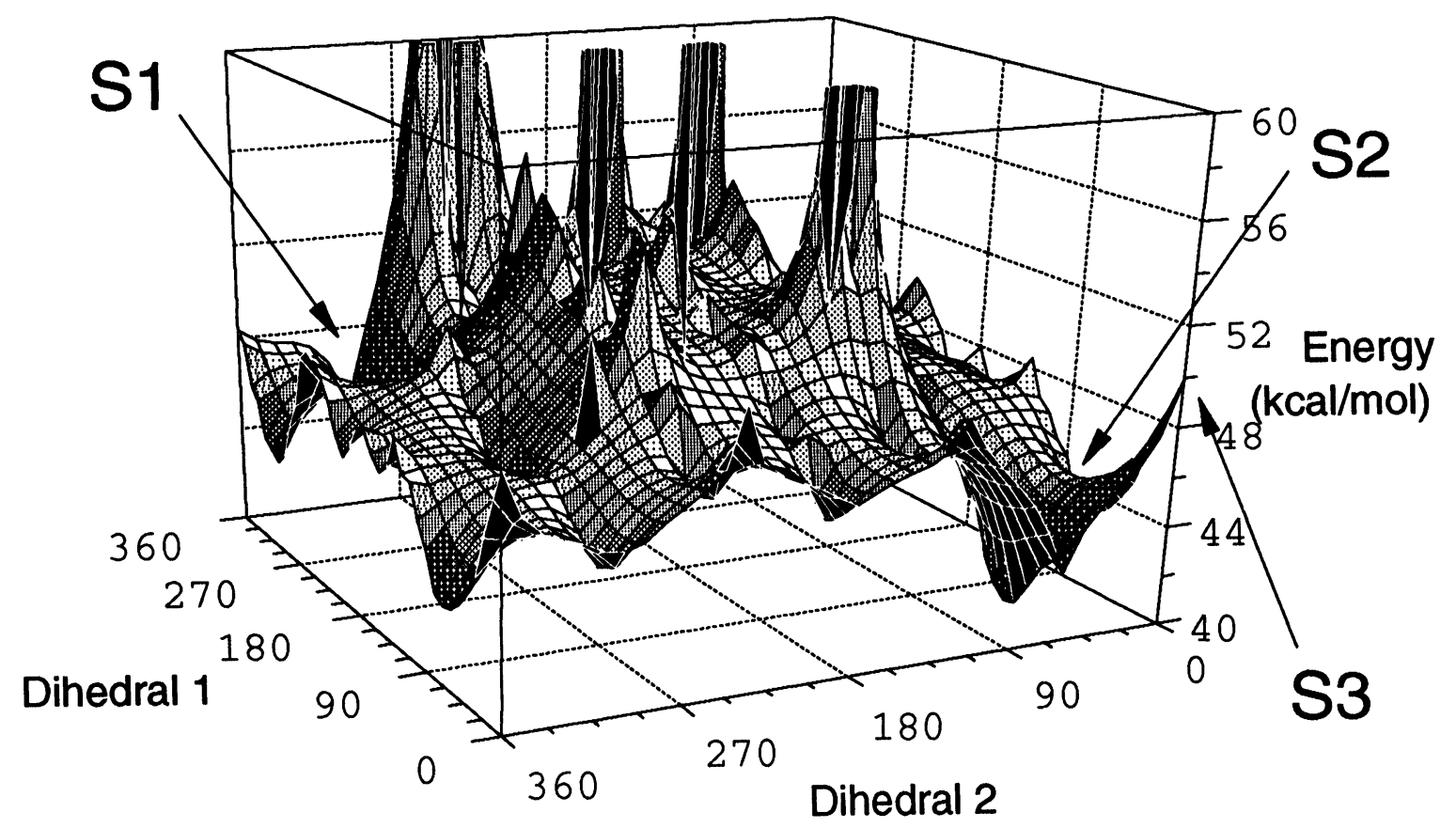

Figure 5. MMX 3-dimensional surface for $\left[\mathrm{Au}_{2}(\mathrm{dppm})(\mathrm{p} \text {-tc) })_{2}\right.$ (A1). S1 and $\mathrm{S} 2$ indicate enantiomers; S3 indicates a structure with the shortest distance between golds.

The 3-D plot is more informative than the 2-D conformational energy profile for the following reasons. First, the symmetry anticipated from the Newman projections but not seen in the 2-D conformational energy profile is now seen in the 3-D plot. The point labeled S2 in Figure 5 corresponds to the conformation near $\phi_{1} \approx 60^{\circ}$, i.e., the global minimum in the 2-D profile (Fig. 4). There is an equal energy conformation labeled S1 that corresponds to the enantiomer of $S 2$. The 3-D plot also reveals a "mountainous" region where clashes between phenyl rings generate very large energy barriers to rotation. It is clearly impossible for S1 and S2 to interconvert along the diagonal. However, interconversion of the enantiomers can occur with an energy barrier as low as $6 \mathrm{kcal} / \mathrm{mol}$ by following a pathway closer to the edges of the 3-D surface.

This is more clearly seen in the contour plot shown in Figure 6. Structure $\mathrm{S2}$ is represented by the region of lowest total energy shown in the lower left hand corner, and $\mathrm{S} 1$ is diagonally opposite. The energies of $S 1(\approx 43.5 \mathrm{kcal} / \mathrm{mol})$ and $S 2(\approx 40.5 \mathrm{kcal} / \mathrm{mol})$ appear to differ by $3.0 \mathrm{kcal} / \mathrm{mol}$. This is an artifact of the way the double dihedral drive computation was carried out, i.e. $\phi_{2}$ was not driven in small enough increments. When the structures $S 1$ and $S 2$ are input as specified by $\phi_{1}$ and $\phi_{2}$ and full geometry minimizations are carried out, the energies differ by $0.2 \mathrm{kcal} / \mathrm{mol}$. Ball and stick representations of $S 1\left(\phi_{1}=64^{\circ}, \phi_{2}=59^{\circ}\right)$ and $S 2\left(\phi_{1}=299^{\circ}, \phi_{2}=303^{\circ}\right)$ are shown in 
Figure 7. The Au-P bonds in each structure are approximately "anti" to each other. We conclude that the enantiomeric structures, $S 1$ and $S 2$ represent the global minimum configuration. There are also several local minima along the surface connecting $S 1$ and $S 2$ that are within 3-4 kcal/mol of the global minimum. For example, the structure in the lower right hand corner of Figure 6 (near $\phi_{1}=300^{\circ}$ ) corresponds to the local minimum conformation at $44.5 \mathrm{kcaV} / \mathrm{mol}$ in the 2-D plot (Fig. 4).

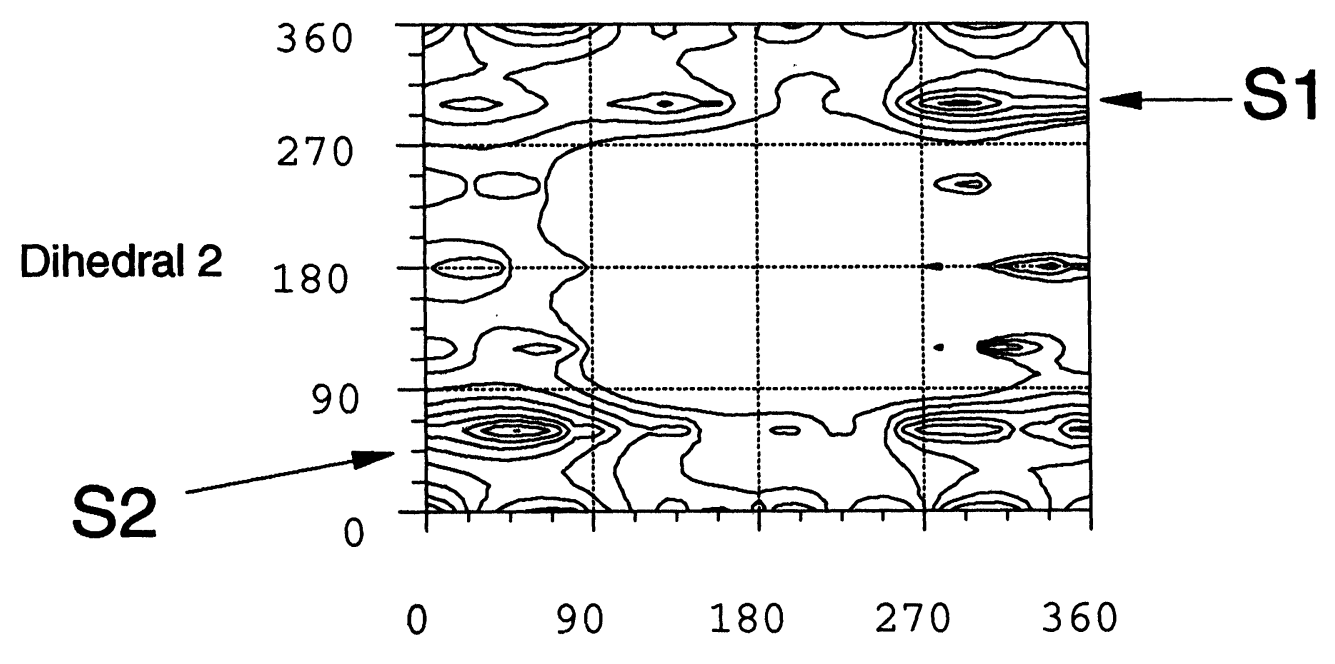

Dihedral 1

Figure 6. $M M X$ contour plot for $\left[\mathrm{Au}_{2}(\mathrm{dppm})(\mathrm{p}-\mathrm{tc})_{2}\right](\mathrm{A1})$. Contour values of total energy were 40.5, $41.5,42.5,43.5,44.5,45.5,46.5,47.5$, and $48.5 \mathrm{kcal} / \mathrm{mol}$.

It is important to point out that interconversion of the global and local minima does not account for the dynamic process observed in the VT-NMR experiments for A1 because the experimentally determined activation energy is $10 \mathrm{kcal} / \mathrm{mol}$, while the activation barrier calculated by $M M X$ is estimated to be no more than $6 \mathrm{kcal} / \mathrm{mol} .12$ Obviously, interconversion of S1 and S2 is also not responsible for the dynamic process because, as enantiomers, they would have the same chemical shift.

In a previous paper, we hypothesized that an intramolecular gold-gold interaction in A1 causes repulsion between sulfur lone pairs and thus destabilizes the HOMO, which is sulfur in character. $5 a$ Does the molecular mechanics calculation support this hypothesis? There are a number of conformations in which the golds are within bonding distance $(<3.4 \AA)$. However, the conformation which has the shortest distance between golds occurs at $\phi_{1}=0^{\circ}, \phi_{2}=0^{\circ}$, labeled S3 in Figure 5 and shown as a ball and stick representation in Figure 7. The Au-P bonds are oriented approximately "syn" to each other and the Au-Au distance is less than $3 \AA$. The MMX calculation does not include parameters for the attraction or repulsion between metal atoms. Accordingly, this conformation is disfavored for steric reasons and is estimated to be about $9 \mathrm{kcal} / \mathrm{mol}$ higher in energy than the global minimum. However, formation of a gold-gold bond in this conformation is expected to contribute electronic stabilization on the order of $8-10 \mathrm{kcal} / \mathrm{mol} .^{13}$ The energy of the gold-gold bonded "syn" isomer would then be within $1 \mathrm{kcal} / \mathrm{mol}$ of the global minimum "anti" conformation. This interconversion of the "syn" gold-gold bonded and "anti" nonbonded conformations is consistent with the dynamic process observed in the VT-NMR experiments (see Scheme II). 


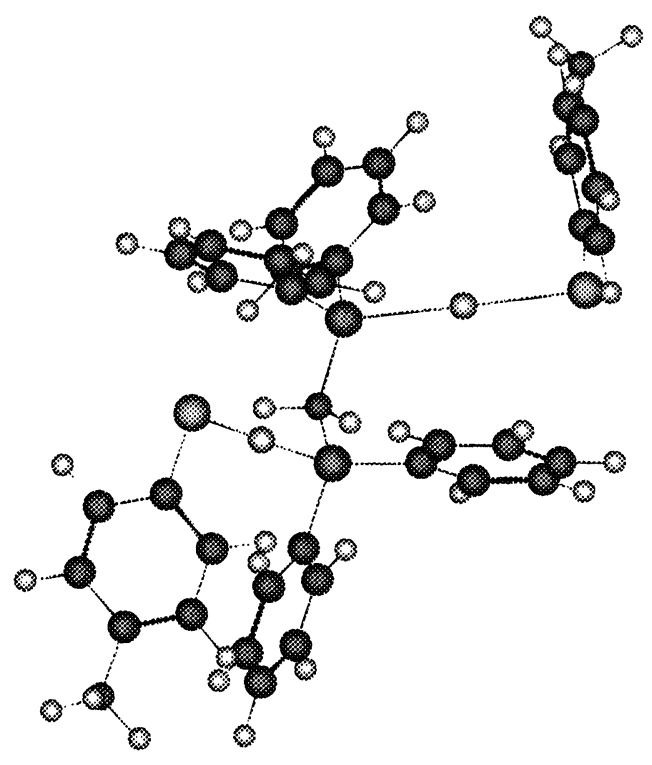

S1

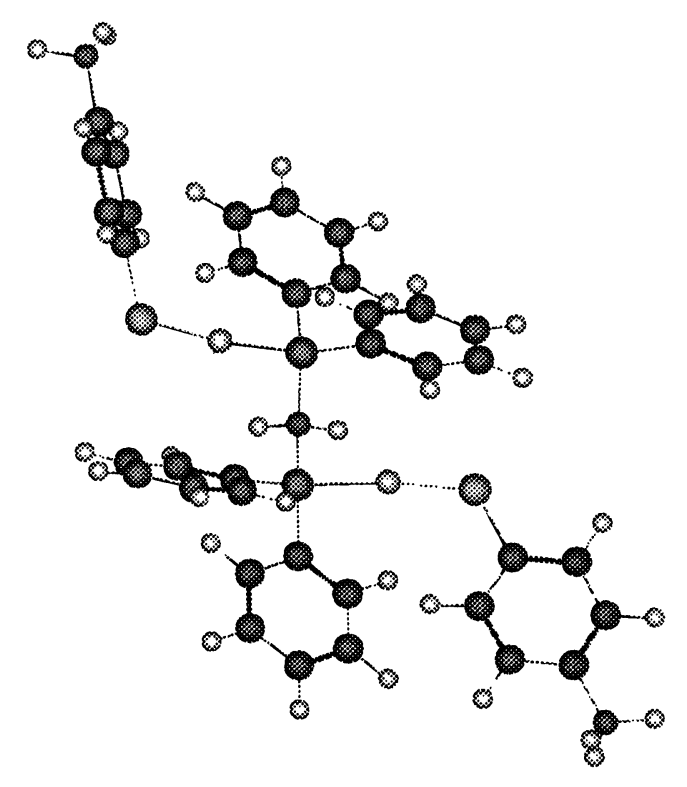

S2

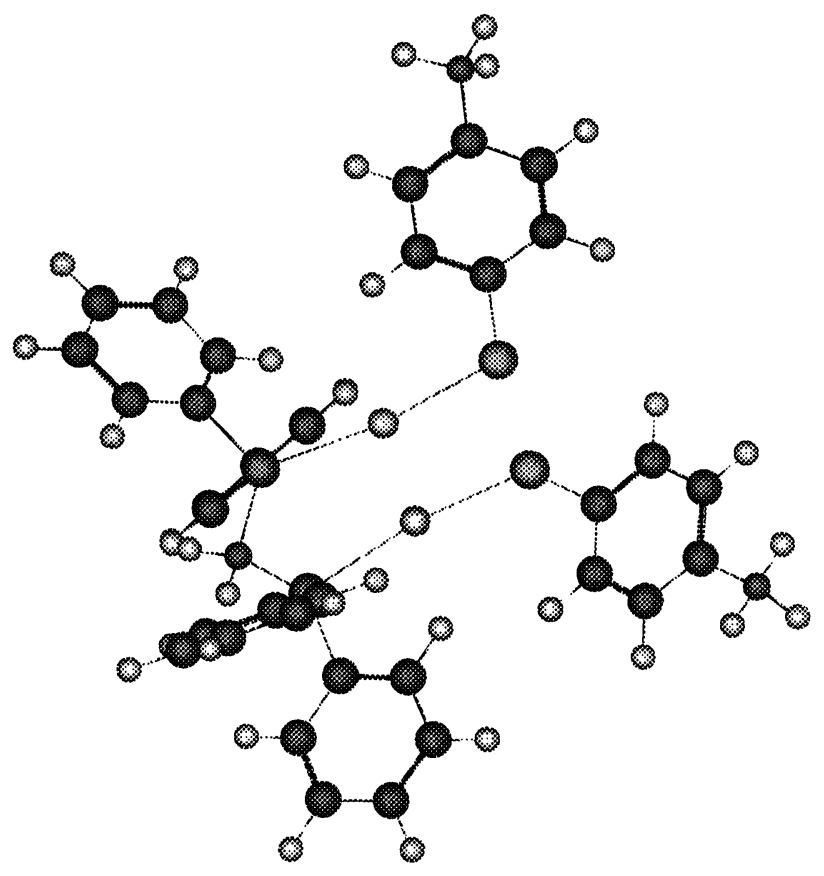

S3

Figure 7. Ball and stick representations of $\left[\mathrm{Au}_{2}(\mathrm{dppm})(\mathrm{p}-\mathrm{tc})_{2}\right](\mathbf{A 1})$ in conformations $\mathrm{S1}, \mathrm{S2}$, and S3. 


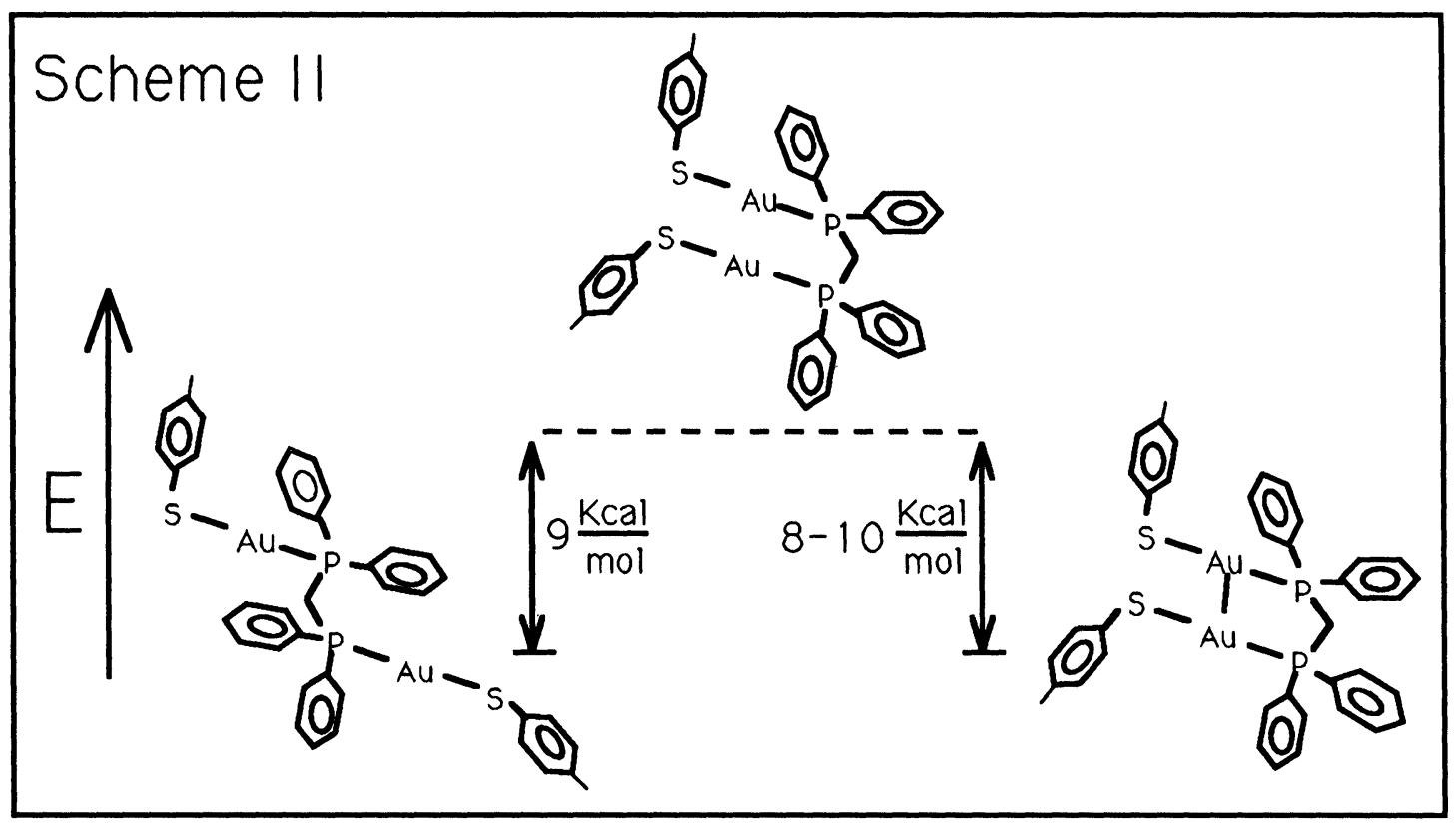

The Effect of Sterically Hindered Thiolates on Gold-Gold Bonds. Examination of the conformational profile of A1 prompted us to investigate how bulky substituents on the thiolate aromatic ring would influence conformational preferences. The complexes shown below in series $D$ were synthesized in which the steric and electronic properties of the substituents on the thiolate ligand are varied. We hypothesized that bulky substituents in the ortho positions would block the close approach of golds whereas meta or para substituents would exert less steric control. As a first approximation our hypothesis appears to be correct because the 2,6-disubstituted complexes are white and show only 1 peak in variable-temperature 31P NMR experiments, while the 3,5-dimethyl and para-substituted derivatives are yellow and show 2 peaks at low temperature. We are continuing to investigate the electronic structure of these complexes to verify this conclusion and the results of electronic spectra analysis will be reported elsewhere. ${ }^{14}$

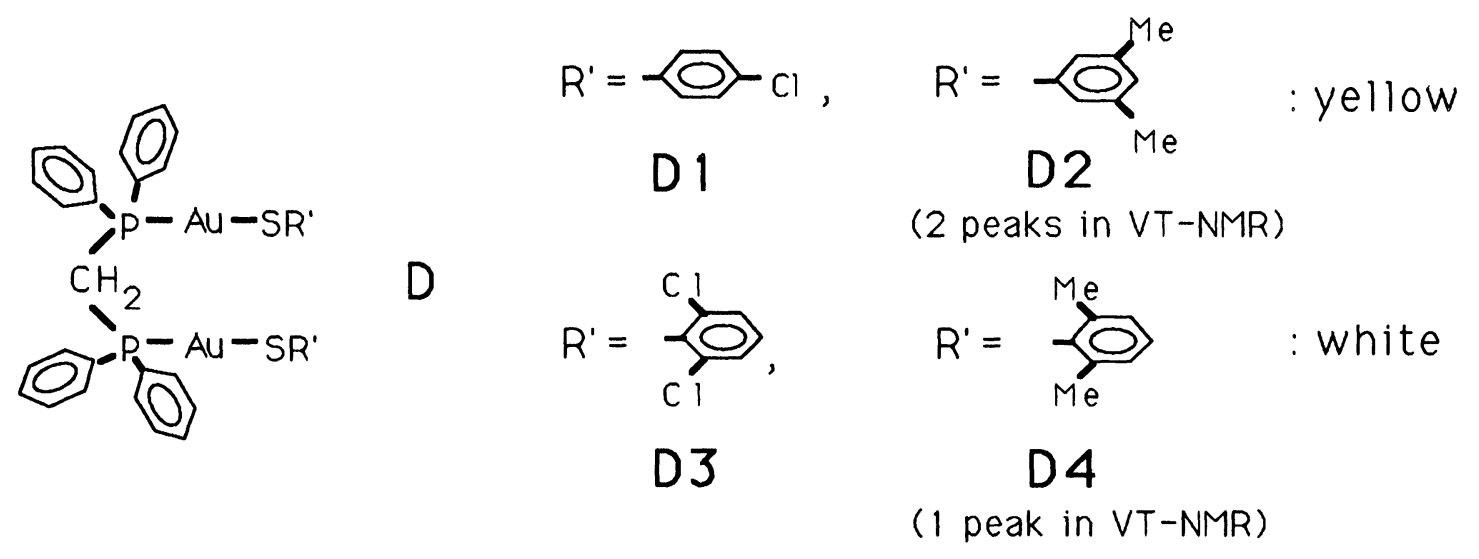

Electronic Structure and Gold-Gold Interactions. A principle piece of evidence for the weak attractive interactions between closed shell gold $(I)$ atoms is provided by $X$-ray analysis of single crystals in which the distance between two gold atoms is significantly less than the van der Waal's 
radii of 3.4 $\AA$.3a We have also recently reported for the first time the detection of gold(I)-gold(I) interactions using Extended X-ray Absorption Fine Structure (EXAFS) experiments conducted at the Stanford Synchrotron Radiation Laboratory by Professor R. C. Elder and his coworkers at the Univ. of Cincinnati. $5 \mathrm{~b}$ Gold-gold interactions are so prevalent in solid state structures of gold(I) complexes that the phenomenon has been dubbed "aurophilicity" by Schmidbaur. 3a Furthermore, short gold(I)-gold(I) contacts are believed to be responsible for some unusual structural features. For example, the structure of the dinuclear complex A4 reveals that the Au-P bonds are approximately anti to each other and the short intermolecular Au-Au distance of 3.094(1) $\AA$ leads to the formation of extended polymers. ${ }^{5 a}$ Schmidbaur and coworkers have recently reported several unusual structures in which "hypervalent" central atoms such as nitrogen or carbon are stabilized by gold-gold interactions. ${ }^{15}$

Establishing the presence of gold-gold interactions in solution is more difficult. We have used molecular mechanics calculations supported by VT-NMR experimental results to give us insight into the possibility of gold-gold bonding in solution. Molecular mechanics calculations have been successfully applied to conformational analyses of transition metal complexes in recent years. ${ }^{16}$ Since force constants associated with $\mathrm{Au}(\mathrm{l})-\mathrm{P}$ and $\mathrm{Au}(\mathrm{l})-\mathrm{S}$ bonds are not readily available, the $\mathrm{MMX}$ force field uses a set of generalized force constants for transition metals. For this reason we have been careful to use the MMX calculations only for a qualitative understanding of the conformational preferences in A1 and A2. The results of molecular mechanics calculations and VT-NMR experiments described above allow us to suggest an explanation for the red shift in the UV-vis spectrum of A1 relative to A2. An intramolecular interaction between gold(I) atoms in the "syn" orientation would tend to increase repulsion between the lone pairs on sulfur. In addition to destabilizing the HOMO sulfur orbitals, a gold-gold interaction is expected to stabilize the LUMO if this empty metal orbital (probably $6 p$ ) contributes to the Au-Au $\sigma$ bond. ${ }^{17}$ The net effect is a red shift in the $S \rightarrow A u C T$ in A1. Although our studies are consistent with gold-gold bonds forming in solution for A1 (and possibly for D1 and D2), the results are not as yet definitive. Establishing whether this phenomena occurs in solution, and how it influences electronic structure and reactivity, is important because it may be critical to understanding the bioinorganic chemistry of gold.

We have recently done an interesting experiment that suggests that gold-gold bonding may influence solution reactivity. Reaction of complex A1 and bis(p-chlorophenyl)disulfide occurs at room temperature and appears to proceed according to the equation shown below. ${ }^{18}$

$$
\begin{gathered}
\mathrm{Au}_{2}(\mathrm{dppm})(\mathrm{SR})_{2}+\mathrm{R}^{\prime} \mathrm{SSR}^{\prime} \rightarrow \mathrm{Au}_{2}(\mathrm{dppm})\left(\mathrm{SR}^{\prime}\right)_{2}+\mathrm{RSSR} \\
\mathrm{A1} \quad \mathrm{R}=\text { 4-methylphenyl, R' = 4-chlorophenyl }
\end{gathered}
$$

Formation of a significant amount of the symmetrical disulfide, RSSR suggests that a gold(I)-gold(I) bond in solution is mechanistically important. Oxidative addition of $\mathrm{X}_{2}\left(\mathrm{X}_{2}=\mathrm{CH}_{3} \mathrm{I}, \mathrm{PhCH}_{2} \mathrm{Br}, \mathrm{I}_{2}\right)$ to cyclic dinuclear $\mathrm{Au}(\mathrm{I})$ complexes with phosphorus ylide ligands generally leads to stable dinuclear $\mathrm{Au}(\mathrm{II}) /(\mathrm{II})$ complexes. ${ }^{19}$ "Anchimeric assistance" by an adjacent $\mathrm{Au}(\mathrm{I})$ may play an important role in these reactions. ${ }^{20}$ By analogy, oxidative addition of R'SSR' may occur across two gold(I) centers, and if the dinuclear complex is in the "syn" orientation, then reductive elimination of RSSR could occur. Formation of RSSR is consistent with an oxidative addition/reductive elimination mechanism. Further experiments are underway to distinguish thermodynamic and kinetic products in the reactions of disulfides with mononuclear and dinuclear gold $(I)$ complexes. 
Acknowledgments. A.E.B. and M.R.M.B. gratefully acknowledge financial support from the National Institutes of Health (Grant AR39858) and the University of Maine BRSG funds. S. Ganesh and $L$. Lester are acknowledged for their technical assistance.

\section{References}

(1) (a) Walz, D. T. Mechanisms of Action of Gold Salts in Rheumatoid Arthritis. In Advances in Inflammation Research; Otterness, I., Capetola, R., Wong, S., Eds.; Raven Press: New York, 1984; Vol. 7, 239. (b) Brown, D. H., Smith, W. E. Chem. Soc. Rev., 1980, 9, 217. (c) Shaw, C. F. Inorg. Perspect. in Biol. and Med., 1979, 2, 287. (d) Sadler, P. J. Struct. Bonding (Berlin) 1976, 29, 171.

(2) (a) Mirabelli, C. K.; Hill, D. T.; Faucette, L. F.; McCabe, F. L.; Girard, G. R.; Bryan, L. B.; Sutton, B. M.; Bartus, J. O.; Crooke, S. T.; Johnson, R. K. J. Med. Chem., 1987, 30, 2181. (b) Okada, T.; Patterson, B. K.; Ye, S. Q.; Gurney, M. E. Virology, 1993, $192,631$.

(3) for a few examples see (a)Schmidbaur, H. Gold Bull., 1990, 23, 11. (b) Pyykkö, P.; Zhao, Y. Angew. Chem. Int. Ed. Engl., 1991, 30, 604. (c) Balch, A. L.; Fung, E. Y.; Olmstead, M. M. J. Am. Chem. Soc., 1990, 112, 5181. (d) Raptis, R. G.; Fackler, J. P., Jr.; Murray, H. H.; Porter, L. C. Inorg. Chem., 1989, 28, 4057. (e) Jiang, Y.; Alvarez, S.; Hoffmann, R. Inorg. Chem., 1985, 24, 749. (f) Pyykko, P.; Desclaus, J. P. Accts. Chem. Res., 1979, $12,276$.

(4) Jaffey, D. M.; Madix, R. J. J. Am. Chem. Soc., 1994, 116, 3012.

(5) (a) Narayanswamy, R; Young, M. A.; Parkhurst, E.; Ouellette, M.; Kerr, M. E.; Ho, D. M.; Elder, R. C.; Bruce, A. E.; Bruce, M. R. M. Inorg. Chem., 1993, 32, 2202. (b) Jones, W. B., Yuan, J.; Narayanaswamy, R.; Young, M. A.; Elder, R. C.; Bruce, A. E.; Bruce, M. R. M. Inorg. Chem., accepted for publication. (c) Turmel, C.; Jiang, T.; Wei, G.; Morrison, R.; Narayanaswamy, R.; Bruce, A. E.; Bruce, M. R. M. J. Am. Chem. Soc. (submitted). (d) Jiang, T.; Wei, G.; Turnmel, C.; Bruce, A. E.; Bruce, M. R. M. Metal-Based Drugs, accepted for publication.

(6) Lever, A. B. P. Inorganic Electronic Spectroscopy, 2nd ed.; Elsevier: Amsterdam, 1984.

(7) The UV-vis spectrum of A2 is nearly identical to that of A5. Complex A2 was selected for comparison to $\mathbf{A 1}$ because the conformational analysis was simpler than for A5.

(8) Serena Software, Box 3076, Bloomington, IN 47402-3076; we thank Kevin Gilbert for a demonstration copy of this software.

(9) Burkert, U.; Allinger, N. L. Miolecular Mechanics, American Chemical Society, Washington, DC, 1982.

(10) Allinger, M. L.; Yuh, Y. H.; Lii, J.-H. J. Am. Chem. Soc., 1989, 111, 8551.

(11) Schmidbaur, H.; Deschler, U.; Milewski-Mahrla, B. Chem. Ber., 1983, 116, 1393.

(12) Conformational energies calculated by molecular mechanics are actually enthalpies. Even if there was a $1 \mathrm{kcal} / \mathrm{mol}$ entropic contribution to the activation barrier, this still would not account for $a \Delta \mathrm{G}^{\ddagger}=10 \mathrm{kcal} / \mathrm{mol}$.

(13) Schmidbaur, H.; Graf, W.; Müller, G. Angew. Chem. Int. Ed. Engl., 1988, $27,417$.

(14) McDougal, K.; Bruce, A.; Bruce, M. manuscript in preparation.

(15) Dufour, M.; Schier, A.; Schmidbaur, H. Organometallics, 1993, 12, 2408 and references therein.

(16) see for example (a) Mackie, S. C.; Baird, M. C. Organometallics, 1992,11, 3712. (b) Polowin, J.; Mackie, S. C.; Baird, M. C. ibid, 1992,11, 3724. (c) Hancock, R. D. in Prog. in Inorg. Chem., 1989, 37, 187. (d) Brubaker, G. R.; Johnson, D. W. Coord. Chem. Rev., 1984, 53, 1.

(17) Stabilization of the LUMO may occur if the $6 s$ or $6 p$ orbitals mix with the $5 \mathrm{dz}^{2}$ orbitals used to form a gold(I)-gold(I) interaction.

(18) Ganesh, S.; Bruce, A.; Bruce, M. unpublished results. 
(19) (a) Murray, H. H.; Fackler, J. P., Jr.; Mazany, A. M. Organometallics, 1985, 4, 154. (b) Basil, J. D.; Murray, H. H.; Fackler, J. P., Jr.; Tocher, J.; Mazany, A. M.; Trzcinska-Bancroft, B.; Knachel, H.; Dudis, D.; Delord, T. J.; Marler, D. O. J. Am. Chem. Soc., 1985, 107, 6908. (c) Fackler, J. P., Jr.; Murray, H. H.; Basil, J. D. Organometallics, 1984, 3, 821. (d) Schmidbaur, H.; Franke, R. Inorg. Chim. Acta, 1975, $13,85$.

(20) Collman, J. P.; Hegedus, L. S.; Norton, J. R.; Finke, R. G. Principles and Applications of Organotransition Metal Chemistry, University Science Books: Mill Valley, CA, 1987, p. 320. 